\title{
Analysis of the Relationship between the Real Estate Fluctuations and Economic Growth Fluctuations
}

\author{
Chengyi Pu ${ }^{1}$, Jing Zhao ${ }^{2}$ \\ ${ }^{1}$ School of Insurance, Central University of Finance and Economics, Beijing100081, China \\ ${ }^{2}$ School of Economics, Southwest University for Nationalities, Chengdu610004, China
}

\begin{abstract}
This article describes the relationship between economic growth and the real estate industry, where the latter is regarded as a part of the market economy. First of two features, trends and volatility analysis of the causes, and the reaction of its change trend by using bar charts, line charts and tables clear and intuitive way, and then put the two together, the whole relationship between the test and Granger by the Association empirical analysis causality test whether there affect the relationship between them and draw conclusions. Finally, the reasons for the 2008 US subprime crisis and Japan's 1990s economic crisis analyzes and lessons learned for the future good development of real estate and economic growth of our suggestions countermeasures.
\end{abstract}

Keywords: Real Estate, Economic Growth, Fluctuation, Risk

\section{Introduction}

\subsection{Background}

The real estate industry is the product of the reform and opening up, and has an obvious promoting effect on the growth of national economy. However, the rise of China's economy is the rise of the real estate industry supported by the

Authors: Chengyi Pu, Professor, Doctorial Tutor, Major in risk management \& insurance. Corresponding Author of this paper. Jing Zhao, Postgraduate Student, Major in mathematic finance $\&$ risk management.

Address: 39 South College Road, Haidian District, Beijing 100081, China

Email: Pucy2011@126.com, Tel: 18908212316 capital market, which is very risky. In November 2015, Meeting of the central financial leadership group introduced the supply-side structural reform. The real estate industry is very rare. Many decisions also refer to reduce the inventory and excess capacity, and to promote the sustainable development. This again reflects our government's determination to regulate the real estate market. In the past few years, the real estate regulation policy has started with housing demand and taking short-term stimulus. However, this method can't solve the problems of real estate industry in China. Now, supply side reform is not only about reducing the inventory, in fact, which is to stimulate the vitality of the market subject and carry out a series of structural adjustment. The combination of supply-side structure and real estate regulation is to change the situation so that real estate developers can provide high-quality housing quality and efficiency. Therefore, embarking from the new economic situation and the government's new "supply side structural reform" policy, this paper analyzes the fluctuation of economic growth and development of China's real estate industry, for the future of the good health to provide relevant measures and suggestions.

\subsection{Literature Review}

Through literature retrieval, many scholars at home and abroad have been analyzes the characteristics, trends a volatility of the real estate and economic growth from the perspective of qualitative and quantitative, especially for the cause of the fluctuations of the real estate industry, the interaction between real estate cycle and economic growth cycle has carried on the detailed analysis 
and research.

The overseas real estate fluctuation cycle is the first to be studied, but they began by studying the internal connection between the construction period and the business cycle. Newman (1935) found that the construction cycle and business cycle of the United States were independent of each other, which had no influence on each other, and the commercial fluctuation had nothing to do with the fluctuation of the construction industry. But Hansen (1941) refutes that view. Through his study of American business prosperity, he found that the cyclical fluctuations of the construction industry were closely linked to the fluctuations of the business cycle. The following research also further confirmed Hansen's view that real estate fluctuation and economic growth fluctuation do have mutual influence relation.

Domestic research of relations between the real estate fluctuation and economic growth carried out late, from the beginning, many scholars make qualitative analysis. To the later, it gradually began to qualitative analyze fluctuation relationship. Sun and Zhang (2009) adopted by the direct method and $\mathrm{H}$ - P filtering method to analyze the China's reform and opening up 30 years of real estate cycle fluctuation and economic cycle, the empirical relationship between concluded that China's real estate industry will present a different length fluctuation cycle time span. Lv and Qin (2011) through to the real estate fluctuation and the relationship between the development of national economy, using the model of granger causality test empirically, concluded that whether there is interaction relationship between different lag period is uncertain. Zhiet. al. (2009) has carried on the empirical analysis, according to China's experience to our country real estate cycle and interactive relationship of economic cycle, using multivariate VAR model, showing that China's real estate industry cycle and interactive relationship exists between the economic cycle.

Wang (2014), using the co-integration analysis and granger test to Guangzhou real estate investment and economic growth relations and empirical analysis are conducted on different lag, found that there is a causal relationship between the two is uncertain.

The above literatures provide many references for us to analyze the relationship between the fluctuation of real estate industry and the fluctuation of economic growth. The analysis of the relationship between the two is not very accurate. Only through the construction model can the relationship be better explained by the quantitative method.

\section{Trend of economic growth and real estate} industry.

\subsection{Characteristics and Trend of Economic} Growth.

It is apparently in growth change that only $6.9 \%$ of GDP in 2015 year-on-year growth rate in China than in 2014 dropped $0.5 \%$ from $7.4 \%$, and in previous years dropped around $10 \%$. Two Sessions still raised the forecast of GDP growth of $6.5 \%-7 \%$, indicating a certain confidence in China's economic growth. In order to reflect the data more directly, the statistical graph is drawn up to make it easier to see the fluctuation of China's economic growth. It can be clearly seen that China's economic growth presents cyclical fluctuations. According to economic cycle theory, from Joseph Schumpeter, an economic fluctuation cycle is divided into four stages: prosperity, recession, depression and recovery. The economic growth of our country can be divided into four major periods in terms of large scale. The first is from 1979 to 1991 with the second from 1992 to 1997, the third from 1998 to 2008 , and the last from 2009 to now. The first cycle is most obvious with the biggest volatility. The main reason is that after this our country implemented the policy of reform and opening and the transformation of economic system, greatly increase the vitality of the economic development in our country. The second and third cycle on the basis of a cycle economy maintained a steady high-speed development, and presented the obvious fluctuation 
characteristics, completed full cyclical fluctuations with the basic stability. The fourth cycle, which began with the us subprime crisis in 2008, has clearly been affected. During this period, the GDP growth rate has declined significantly, especially in the last two years (Fig.1).

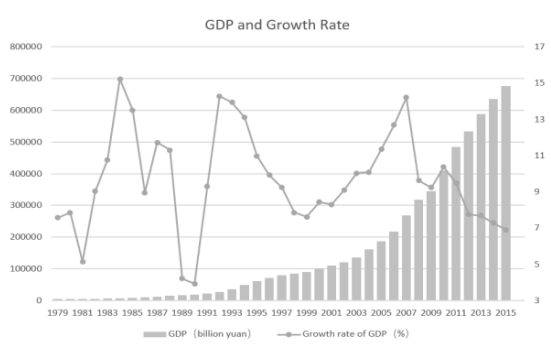

Fig.1 Growth Rate of GDP

2.2 Characteristics and Trends of China's Real Estate Industry.

Since 1998, China has abolished the system, and the housing problem has been changed from the original welfare to the market. Just 20 years, the real estate investment always keeps high-speed growth, even though the government also have been introduced related policy regulation of the real estate to maintain reasonable prices. The following chart also reflects the growth of China's real estate industry from 1988. The real estate industry, as a part of the macro economy, also has the fluctuation period, which can be divided into two periods. The first was from 1987 to 1998 with the second from 1999 to present. It is clearly from the figure, that the real estate industry fluctuates particularly big and obvious before the end of welfare housing distribution in our country. In the second cycle, we can clearly see that the real estate development investment grows rapidly, but its growth rate fluctuation is not particularly big (Fig.2).

3. The Influence Mechanism of Economic Growth and Real Estate Industry

3.1 Qualitative Analysis of the Influence

Mechanism of Economic Growth and Real

\section{Estate Industry}

The real estate industry is the most important part of the national economic growth. Now, putting

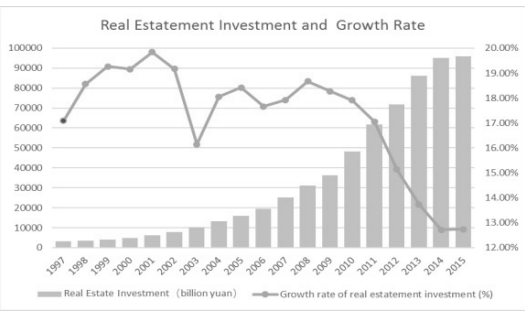

Fig.2 The Growth Rate of Real Estate Investment

the two together, it's not hard to see that they both have the same fluctuation, just the difference in the frequency and the amplitude of the wave. Behind the obvious fluctuation of real estate growth rate is the result of economic factors, policy factors and supply and demand factors of real estate market. The fluctuation period of the real estate industry is generally short, so it is also more frequent. And the economic growth fluctuation period is long for the experience time is long. Since 1998, the level of GDP growth in China has been maintained at 7 percent to 13 percent with a relatively stable fluctuation, which is inseparable from the high quality management of the country. While the growth rate of real estate development and investment fluctuated greatly. Obviously, China's real estate market are kept at the growth rate of a very high level from 2000 to 2011 with the large amount of investment in real estate, which easily leads to the emergence of the real estate bubble (Fig3.).

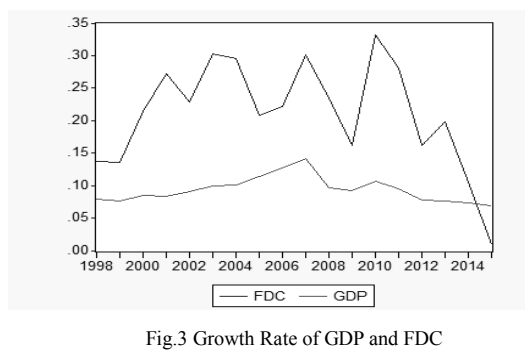

After so many years of development, the relationship between the real estate industry and the economic growth is getting closer and closer. Changes in national economic growth can directly or indirectly affect real estate through national 
income, investment quantity, money supply and interest rate. The real estate industry is the most sensitive to macroeconomic changes, which is determined by its own characteristics as the basic industry of national economy and the characteristics of pillar industries. China's economic growth is mainly driven by investment, and real estate investment has the greatest impact on it. In addition to the investment, the bank's money supply has a huge impact on the real estate industry. Real estate developers need a lot of money to develop and invest, and commercial Banks are often their source of funds, then they have derived real estate finance. The relationship between the real estate industry and the financial sector is very close, and it is likely that the financial crisis will occur if we do not control it. In addition to the money supply, the macroeconomic factors affecting the real estate industry are interest rate and inflation rate. In general, when interest rates are lowered, the cost of obtaining a loan is reduced correspondingly, and the housing demand is strong, which eventually leads to the boom in real estate. When inflation rates are too high, people are more likely to use the money in their hands to buy things, and most people prefer to buy homes for investment. At this time, the increase of housing demand will attract more real estate agents to enter, thus promoting the development of the real estate industry. In the past years, China's economic rise has largely depended on the rapid development of real estate industry, real estate industry is the most powerful pull of China's economic growth momentum, which has contributed a lot to the GDP growth. More importantly, because of the nature of the real estate industry: auxiliary and relevance. We often ignore that it's driving a lot of related industries, for example, energy, finance, and specific industries, including construction, metallurgy, transportation, and so on. These are long chain industries related to real estate, and they also support the growth of national economy.

\subsection{Quantitative Analysis of the Influence Mechanism of Economic Growth and Real Estate Industry}

Above content are qualitative analysis through the charts of the relationship between economic growth and the real estate industry, the following us by constructing the model on the relationship between the two from the perspective of quantitative validation, this paper adopts Eviws5.0.

\section{(a) Data sources and processing}

This paper selects the gross domestic product (GDP) and real estate development investment (FDC) from 1998 to 2015 as the data to analyze the relationship between the fluctuation of the economic growth and the fluctuation of the real estate industry. They are chosen because they are the most representative of all indicators that reflect gross domestic product (GDP0 and FDC). Generally, in econometrics, the analysis of the time series data, should first take the natural logarithm of time series data, which is in order to eliminate the influence of the time series data heteroscedasticity.

Through the above test results, you can see that the original time series data of Ln (GDP) and Ln (FDC) is not smooth, so we get the first order difference of Ln (GDP) and Ln (FDC), after processing, the results through Eviews software showed that both at this time has the stability, and there may be a cointegration relationship between the two.

\section{(b) Inspection of co-integration relationship}

Specifically, this article illustrates the cointegration relationship of inspection in China between 1998 and 2015 gross domestic product (GDP) and real estate development investment (FDC) to find whether there is a long-term stable equilibrium relationship. If we want to show that the two are in equilibrium, the deviation is zero. But there will be a non-equilibrium error, which is normal. The most commonly used method of testing cointegration relationship is OLS method to cointegrate the variables. $\operatorname{Ln}(\mathrm{GDP})$ is the 
dependent variable of regression equation, $\ln (\mathrm{FDC})$ is the independent variable, and the two variables using OLS method cointegration regression, equation is as follows:

$$
Y=\beta_{0}+\beta_{1} X+u
$$

Using Eviews software after cointegration regression, the results shown in the figure below. According to the numerical analysis software, the regression equation for

$$
\operatorname{Ln}(G D P)=9.25+1.56 \times \operatorname{Ln}(F D C)
$$

Of which R - squared value of 0.994281 , tend to be 1 , visible fit of the model is very high, so the logarithm of GDP and the logarithm of real estate, and long-term stable equilibrium relationship between which there is a cointegration relationship.

\section{(c) Granger Causality Test}

According to the theorem of granger causality test, two of the unsteady time series variable, we should use error correction model to represent the linear relationship between them if there is an integration relationship. After the error correction model is completed, we can start the granger causality test. Although through the integration test, we can conclude that there is a long-term and stable equilibrium relationship between China's GDP and the real estate development investment, but there is a causal relationship between them and who the cause is and the result is uncertain.

We can then use the Eviews software for Grange test. Then, the result is given in Table 1.

Table 1. Results of Granger Causality Test

\begin{tabular}{|c|c|c|c|c|}
\hline Granger causality & L & F & P & Re \\
\hline Ln(G)don't cas Ln(F) & \multirow{2}{*}{1} & 2.224 & 0.158 & Y \\
Ln(F) don't cas Ln(G) & & 7.203 & 0.017 & N \\
\hline Ln(G) don't cas Ln(F) & \multirow{2}{*}{2} & 0.009 & 0.990 & Y \\
Ln(F) don't cas Ln(G) & & 1.040 & 0.385 & Y \\
\hline Ln(G) don't cas Ln(F) & \multirow{2}{*}{3} & 0.588 & 0.639 & Y \\
Ln(F) don't cas Ln(G) & & 2.520 & 0.131 & Y \\
\hline Ln(G) don't cas Ln(F) & \multirow{2}{*}{4} & 1.345 & 0.369 & Y \\
Ln(F) don't cas Ln(G) & & 0.411 & 0.795 & Y \\
\hline
\end{tabular}

The above test results are compared with the significance level of $5 \%$. Only when the probability value is greater than $5 \%$, accept the null hypothesis or reject it. From the above data, the lag of 2 and 4 years, because of their probability value is higher than $5 \%$, there is no mutual influence relations between independent of each other. The lag period is 1 year, GDP is not the granger cause of FDC, but FDC is the granger reason of GDP, at this time is only one-way causal relationship between them, namely, the real estate industry has an impact on the national economy, but the national economy has an impact on the real estate industry is not necessarily.

\section{Results and Discussion}

\subsection{Result}

After the above qualitative and quantitative analysis of relationship between economic growth and fluctuation of real estate industry in our country, we can draw the conclusion that there is a long-term and stable equilibrium relationship between the real estate industry and national economy in our country. But no matter from the perspective of qualitative and quantitative point of view, the real estate industry has an influence on the development of our national economy, but it is uncertain whether the national economy has an influence on the real estate industry in China. In the late period, GDP is not the granger cause of FDC, but FDC is the granger cause of GDP, and the national economy is not the cause of the development of the real estate industry. This situation is closely related to the actual situation in our country, and it is also related to the special commodity of housing. On the one hand, because the land belongs to the scarce resources, housing has been a necessity in people's lives, and the increasing demand for homes will surely attract more real estate developers to invest in, which can promote the development of the national economy very well. On the other hand, due to the real estate industry is capital-intensive industry with a long industry chain. It can drive the development of many other industries, such as energy, transport, finance, etc., which is more important for the steady growth of the national economy. 


\subsection{Discussion}

Throughout the world's economic history, there have been many examples of the housing bubble that triggered the financial crisis. The most serious economic crisis, in Japan and the United States, has been linked to the housing bubble, both of which have similarities and differences. Japan's economic growth quickly slipped from the peak to the trough and became a national economic crisis. When the bank of Japan raised interest rates to $4.25 \%$, sensitive big investors began selling stocks in large Numbers, and then ordinary investors began to sell stocks wildly, finally, Japanese stocks fell sharply. The collapse of the stock market has triggered a series of chain reactions that have devastated Japan's financial sector and devastated Japan's economy. History does not repeat itself with striking similarities. The subprime mortgage crisis in the United States in 2008 was derived from the real estate industry. One of the most causes of the subprime mortgage crisis is that American Banks and other financial institutions provide credit funds for borrower without enough credit ratings and guarantee ability. This means that borrowers can buy homes without having to use their own capital, and can buy homes entirely by borrowing from Banks, which magnifies the risk. From the perspective of the economic crisis of Japan and the United States, the real estate asset price bubbles are the key factor in a country's economy in trouble. China should learn from this in the future when develop real estate industry and economy.

China's stock market has been underperforming since last June, with concerns that China's current economic and financial market conditions are similar to those of Japan in the 1990s. Japan's economic boom in the 1990s ended in a stock market crash and a housing bust. In the past few years, China's virtual economy and real economy have created a new record. Comparisons between today's China and Japan in the 1990s are valid. Just like at the beginning of Japan, China is also trying to want to cool the real estate market and the stock market. When we see so many similarities, do we really need to think about the economic crisis in China as it did in Japan? These shadow Banks are often the real source of capital for real estate developers, who have received funding from trusts, entrusted loans and other products. If problems in the real estate industry lead to a rupture of the capital chain, the financial risk of shadow banking will also explode. From these aspects, our country's economic and financial situation also has a great hidden danger, facing multiple risks, and the authorities should be actively prepared to guard against risks. In many areas of the real economy, many industries have serious overcapacity, such as steel, cement, solar panels and other industries. Real estate and overcapacity are exacerbating the risk of the country's financial system.

\subsection{Suggestions}

Our government must develop a reasonable and stable policy timely according to the problems, effectively avoid the occurrence of speculative and blindness. In terms of fiscal policy, China's government can fully promote the reform of "replacing business tax with value-added tax", and the real estate industry is included in the pilot scope. In addition, the Chinese government can improve the fiscal deficit according to the phase, increase the national debt issuance and other means to our country economic growth and the real estate industry in macroeconomic regulation and control. In monetary policy, we should continue to implement a prudent monetary policy and create an appropriate monetary policy environment for structural reform.

Chinese commercial Banks and other financial institutions should strengthen the audit of housing loans, but should not relax loan approval conditions with blindly mortgages in order to pursue interests, it is important to ensure that loans are used for the authenticity and loan security. China's financial institutions must learn from the subprime crisis and 
impose strict credit checks. For real estate developers, real estate developers should enhance the social sense of responsibility, should not be mercenary. Since the inadequate housing supply in the market, developer still hold plenty of land resources for own interests.

\section{Conclusion}

The real estate industry is closely related to people's livelihood. As the pillar industry and basic industry of China's national economy, it is necessary to study the fluctuation relationship between China's economic growths. Many experts and scholars began to study the fluctuation relationship between the two, and also obtained the mechanism of the interaction between them. But the economic situation is changing at any time, and the two years of our economy are facing a bigger test. In the face of the current economic downturn and inflation pressure, based on long-term, our government proposed the "supply-side structural reforms" strategy, trying to digest real estate stocks, making efforts to provide better housing for the majority of people in products, to better serve the needs of people's live and life. From this point of view, it is more realistic to study the relationship between the real estate industry and the fluctuation of economic growth. Although the article adopts the method of analysis has not changed with previous empirical analysis method, by building a simple model, cointegration test and Granger causality test, but by collecting the latest data can obviously feel out our country's real estate industry is not as hot as before, and it's more complicated and harder to analyze. In recent years, domestic and international economic environment is not ideal with economic stagnation. The relationship between virtual economy and real economy is becoming more and more subtle. It is hard to differentiate speculation and investment behavior. The voice of people who turn negative on the Chinese economy is becoming more and more intense, and the real estate bubble also became a hot topic. Faced with so much judgment and suffering, we only have to learn more about economics and learn more about the mechanism of action, and strive to be a rational consumer and investor.

\section{Acknowledgments}

This research project received China central and provincial governments' financial support. Part of the research results have been shared with relevant government offices and real estate companies in China. Feedback from them is very positive. The whole research project has been virtually completed and authors are working on editing the final version of the report.

This study was supported by the Central Universities Fund of SWUN (Project Number: 2014SZYTD01), the National Social Science Foundation of China (Project Number: 16BJL115), China Postdoctoral Fund (2011M501409, 2013T60851). We are grateful to reviewers and editors for their insightful comments on this article.

\section{Reference}

[1] Lu C Z, Qin J. Empirical test of the relationship between real estate industry and national economic development. Commercial Economic Research, 2013, (10): 125-127.

[2] Zhao J B. Research on the relationship between Zhouqu of real estate industry and its macro-economy--taking Tianjin as an example. Journal of North China Electric Power University (Social Science), 2015,(6): 41-46.

[3] Zhou Z C, Li Z, Mao J. Study on the Interaction between the real estate cycle and the economic cycle -- empirical data from China. Journal of Nanjing University (Social Science), 2015, (6): 47-57.

[4] Wang S, Chen Z W, Liu S. Analysis on the relationship between real estate investment and economic growth in Guangzhou. Journal Of South China Normal University (Natural Science Edition), 2015,47(4):135-140.

[5] Sun Y J, Zhang Q J. Empirical analysis of China's real estate cycle fluctuation and economic cycle (1979-2008). Productivity 
Research, 2009, (15):87-89.

[6] Pi S, Wu K P. the causal relationship between the development of real estate market and economic growth -- an empirical analysis of China. Management Review, 2004, (3):8-12.

[7] Zheng S Q. Analysis and countermeasures of the influence factors of real estate economic fluctuations. Academic BBS, $2014,(10): 74-78$.

[8] Yang Y H. Analysis of factors affecting the fluctuation of real estate economy and countermeasures. New Economy, 2015, (11):54.

[9] $\mathrm{Li} \mathrm{H} \mathrm{B.} \mathrm{Looking} \mathrm{at} \mathrm{China's} \mathrm{real} \mathrm{estate}$ development from the economic cycle. Economic Problems, 2006, (9):22-23.

[10] Tan B K. Analysis of factors affecting the fluctuation of real estate economy and countermeasures. Time Finance, $2014,(11): 26-34$.

[11] Li Z Y, Li Z Y. Real estate and national economy: an empirical study based on Shenzhen and Chengdu. Industry BBS, 2007, (20):107-108.

[12] Wu S, Measurement technology analysis of real estate investment and economic growth in China. Economic and Management Research, 2010, (1):22-25.

[13] Li N, Wu W Q, Chen M. Research on the structural change of Chinese real estate investment and national economic relations. Mathematical Statistics and Management, 2012, (11):1061-1072.

[14] Chang Z Z. Adjustment of real estate bubble, financial crisis and china's macroeconomic policy. Economic Research Reference, 2010,(70):69-76.

[15] Liang Y F. Empirical analysis on the coordinated development of real estate market and national economy. Chinese Social Science, 2006, (3):74-84.

[16] Zhang L, Chen M Y. Research on the relationship between China's real estate industry and economic growth. Journal of Nanjing University of Technology, 2002,
(3):68-70.

[17] Zheng S Q, Liu H Y. Measurement model and analysis of the relationship between China's construction investment and economic growth Journal of Tsinghua University (Philosophy and Social Science Edition) 2001, (4):45-49.

[18] Wei Z H. Research on the impact of housing and real estate industry on economic growth from the perspective of national economic accounting -- taking Sichuan as an example. Southwest Finance 2013, (9):38-40. 